\title{
Digestive ecology of two omnivorous Canarian lizard species (Gallotia, Lacertidae)
}

\author{
Alfredo Valido ${ }^{1}$, Manuel Nogales \\ Departamento de Biología Animal (Zoología), Universidad de La Laguna, E-38206, Tenerife, Canary Islands, \\ Spain \\ ${ }_{1}^{1}$ Author for reprint request; current address: Dept. of Ecology and Genetics, Aarhus University, Ny Munkegade \\ Building 540 DK-8000 Aarhus C, Denmark \\ e-mail: alfredo.valido@biology.au.dk
}

\begin{abstract}
Omnivorous endemic Canarian lacertids (Gallotia atlantica and G. galloti) do not present any specific digestive and physiological adaptations to herbivorous diet, compared to species and populations with a different degree of herbivory in the Canarian archipelago. The only characteristics that could be related to the type of diet were the number of cusps per tooth (between species) and the number of small stones contained in droppings (between species and populations). The rest of measured traits were correlated with lizard size and for this reason G. galloti has longer intestines, heavier stomachs and livers, more teeth and cusps, and longer gut passage. These data suggest that body size is a major determinant of the reliance on plant food (mainly fleshy fruits) in these lizards and facilitates mutualistic interactions with fleshy-fruited plant species.
\end{abstract}

\section{Introduction}

Structural and functional adaptations of the digestive system for optimal processing of plant matter have been described for several omnivorous and herbivorous vertebrates (see reviews in Lönnberg, 1902; Ziswiler and Farner, 1972; Skoczylas, 1978; Chivers and Hladik, 1980; Guard, 1980; Sibly, 1981; Jordano, 2000).

Although a low proportion (about 2-3\%) of known lizard species eat some quantities of plant food (Pough, 1973; Iverson, 1982; King, 1996), several morphological, anatomical and physiological modifications have also been described for herbivorous lizards (Gekkota, Iguania, and Scincomorpha), which may increase the digestive efficiency of lizards feeding on this resource (Throckmorton, 1973; Johnson and Lillywhite, 1979; Zimmerman and Tracy, 1989). The most important of these traits are: larger body size (Szarski, 1962; Sokol, 1967; Pough, 1973; Iverson, 1982; Schluter, 1984, but see Van Damme, 1999); tendency to show a larger intestine/SVL ratio (Skoczylas, 1978; Van Devender, 1982; Dearing, 1993); 
longer transit time that permits a suitable degradation of plant tissues (Christian et al., 1984; Troyer, 1984; Karasov, 1986; Waldschmidt et al., 1986; Zimmerman and Tracy, 1989; Van Marken Lichtenbelt, 1992); smaller stomachs (Skoczylas, 1978); three-cusp or polycusp dentition (Hotton, 1955; Sokol, 1967; Montanucci, 1968; Greer, 1976; Iverson, 1982; Mateo and López-Jurado, 1992); intestinal caeca and compartmentalization of the colon (Iverson, 1982; Zug, 1993); and the tendency to ingest small stones (Sokol, 1971; Skoczylas, 1978).

Modifications to lizard digestive systems have been described mainly in folivorous species and their presence has been justified, by the need to process fiber-rich plant components, more difficult to digest (Iverson, 1982; Cooper and Vitt, 2002). However, little is known about the digestive modification of lizards that primarily feed on other, comparatively easy to digest, plant components (basically fruits, flowers and nectar) although, in some cases, the proportion of this plant component in the diet is considerable. Generally, lizards inhabiting island habitats have a tendency towards a more herbivorous diet than lizards on mainlands (Van Damme, 1999; Cooper and Vitt, 2002); this is the case of the endemic Canarian lacertids (g. Gallotia), which present the most herbivorous species within Lacertidae (Valido, 1999; Van Damme, 1999). The seven extant Canarian lacertids can be considered omnivorous, but the contribution of plant matter in their diet varies according to lizard species, body size, habitat, and season of the year (e.g. Mateo and López-Jurado, 1992; Valido and Nogales, 1994; Pérez-Mellado et al., 1999; Valido, 1999). However, in some cases (e.g. G. galloti from xerophytic zones in Tenerife), the plant component (basically fleshy fruits) is predominant through the year (Valido, 1999).

The primary aim of this study is to characterize the assemblage of traits in some Canarian lizards. We selected a pair of species that are more distant their diet along an omnivorous gradient: G. atlantica from Fuerteventura, which is omnivorous but basically insectivorous, and three distant populations of G. galloti from Tenerife (Teno Bajo, Bajamar e Izaña), which vary in the importance of the plant component in their diet (from omnivorous, basically insectivorous to omnivorous, mainly herbivorous).

Lizards of the genus Gallotia (Lacertidae) represent an oceanic radiation of reptiles endemic to Canary Islands and are resolved as a basal taxon in the family Lacertidae (Fu, 1998). This genus is characterized by seven extant species and one extinct taxon. This genus has a monophyletic origin and the radiation took place along an eastern-western geographic gradient from the mainland (González et al., 1996).

Gallotia atlantica inhabits Fuerteventura and Lanzarote; it is the smallest species of the genus (adult SVL mean $\pm s=60.8 \pm 9.9 \mathrm{~mm}$; Valido, 1999) and shows an omnivorous diet, although animal components are the main preys. Gallotia galloti inhabits the islands of Tenerife and La Palma; it is a medium-sized lizard (SVL: mean $=106.4 \pm 12.1$; Valido, 1999) and is characterized by an omnivorous diet in which fleshy fruit is the principal component in those populations inhabiting altitudinal lower zones (Valido and Nogales, 1994; Valido, 1999). 
If the traits described above represent adaptations for an herbivorous diet, we would expect the more insectivorous populations (G. atlantica from Fuerteventura and G. galloti from Izaña in Tenerife) to have similar characteristics (shorter intestines and transit period, heavier stomachs, presence of mono/bicuspid dentition) and to differ from the two more herbivorous populations (G. galloti from Teno Bajo and Bajamar). However, an alternative hypothesis is that these lizards do not need special anatomical traits like true herbivorous lizards (Iverson, 1982; Cooper and Vitt, 2002), since the principal parts of the plant in the diet are fleshy fruits and flowers.

The use of these species can also help us to understand the mechanisms influencing dietary variations among insular lizard populations, specifically the general trend for relatively more herbivorous diets when compared to continental areas (Van Damme, 1999; Cooper and Vitt, 2002). This insular trend to increase herbivory (mainly fruits) has also important ecological and evolutionary implications for mutualistic interactions with fleshyfruited plant species in islands (Valido, 1999), a phenomenon which seems to occur more frequently in island ecosystems (Olesen and Valido, 2003).

\section{Material and methods}

The lizards under study were captured in July 1994 at four different localities on two islands: G. atlantica in Fuerteventura (Valle de Tetir - $400 \mathrm{~m}$ a.s.l.; Tetir hereafter) and G. galloti in three different habitats of Tenerife (Barranco de Las Cuevas, Teno Bajo - $150 \mathrm{~m}$ a.s.1.; Barranco de Vargas, Bajamar - $110 \mathrm{~m}$ a.s.1.; and Corral del Niño, Izaña - 2293 m a.s.l.; hereafter Teno Bajo, Bajamar and Izaña, respectively).

The climate of Tetir is characterized by an annual rainfall of less than $200 \mathrm{~mm}$ and mean temperature of $21^{\circ} \mathrm{C}$. Characteristic plants of these xeric zones are Launaea arborescens (Compositae), Salsola vermiculata (Chenopodiaceae), and Lycium intricatum (Solanaceae). In Teno Bajo, the climate is dry, with an annual rainfall $<300 \mathrm{~mm}$, and a mean temperature of about $21^{\circ} \mathrm{C}$. The more abundant plants in this habitat include some species belonging to the genus Euphorbia: E. obtusifolia, E. canariensis, E. balsamifera. In addition, Plocama pendula, Rubia fruticosa (Rubiaceae) and the introduced Opuntia dillenii (Cactaceae) are abundant. The other locality on Tenerife (Bajamar) presents a mean annual rainfall $<400 \mathrm{~mm}$, a mean temperature of $21^{\circ} \mathrm{C}$ and is characterized by scrub vegetation where Asparagus pastorianus, A. umbellatus (Liliaceae), and Bosea yervamora (Amaranthaceae), are abundant. The third locality on Tenerife, Izaña, is a high mountain site with a cool, dry climate and annual rainfall of about $600 \mathrm{~mm}$ and mean temperature of $10^{\circ} \mathrm{C}$; in winter, rainfall can turn to snow. Spartocytisus supranubius and Adenocarpus viscosus (Fabaceae) compose shrubs basically.

Procedures. We collected recent lizard droppings ( $n=150$, at each site) in each of the four localities, in July 1994, in order to study the diet composition. Therefore, in order to cover those different microhabitats within each locality and to have a representative approximation of the lizard diet at population level, linear transects were carried out. To avoid seudoreplication during the sampling collection, no more than five lizard droppings were collected at the same site. Each dropping was kept individually and analyzed under $16 \times$ magnification after the material had been soaked in water. We visually estimated the percentage volume in each faecal sample made up by animal and plant matter (to the nearest 10\%), and the number of animal items and seeds were recorded and identified. Small stones inside droppings were also noted. Although this method is less accurate than stomach contents to trying to know a taxonomic description of invertebrates components, in the approximation carried out in this study (animal $v s$ vegetal component), feces analyses gave similar results to those from stomach (angular transformation on percentages of plant matter; ANOVA, $F=0.016, \mathrm{df}=1,118, P=0.89$ for comparative data obtained from both stomach-flushings from 60 lizards and 60 fresh droppings collected in the same days and sites in Teno Bajo; Valido, 1999). 
The experiments carried out to assess the gut passage time (hereafter GPT) were performed by using 20-21 different adult lizards from three localities (not Bajamar) (12 males and 9 females from Teno Bajo and Izaña; 11 males and 9 females from Tetir) during August to September 1994. They were put in adjacent $32 \times 23 \times 22 \mathrm{~cm}$ individual cages. These cages were located an environmental chamber where the temperature varied between $28-30^{\circ} \mathrm{C}$ and daylight period was $12 \mathrm{~h}$. Each individual was previously acclimatized for 20 days before starting the trials. This temperature range was chosen in accordance whit the operative temperature of these lizards (see Díaz, 1994 for G. galloti and Márquez et al., 1997 for G. atlantica). All individuals had ad libitum access to a diet consisting of insects (adult crickets and Coleoptera larvae) and fruits of 'Balo' (Plocama pendula) and tomatoes (Solanum lycopersicum, Solanaceae). However, insects were always the principal remains in the droppings of all individuals since they prefer this food to fruits when they are present; water was also continuously available.

Lizards were simultaneously force-fed two small glass beads (maximum diameter $=3 \mathrm{~mm}$; mass $=0.02 \mathrm{~g}$ ) together with food. Cages were inspected every three or four hours and faeces were crushed and visually examined for glass beads. Individual GPT was defined as the average time until appearance in the droppings of the two glass beads. Body mass was recorded at the beginning and end of the trials, and remained constant for the lizards from Izaña (Wilcoxon test, $Z=1.08, P=0.27)$ and Tetir $(Z=1.53, P=0.12$ ) while the lizards from Teno Bajo were heavier (about $2.8 \mathrm{~g}$ increase) at the end of the trials $(Z=3.17, P=0.002)$.

To test if the data from the laboratory trials were similar to natural conditions, we made parallel experiments in the field (Teno Bajo). We put 13 adult lizards in individual cages $(40 \times 30 \times 25 \mathrm{~cm})$ and they had ad libitum access to food (the same provided in the captivity trials) under conditions of sun/shade. Lizards were also forcefed simultaneously two glass beads with the food. Taking into account that GPT is influenced by the SVL of each individual, lizards from the field (average \pm S.D.; $104.9 \pm 10.8 \mathrm{~mm}, n=13$ ) showed no significant size differences from those used in the laboratory experiments $(111.2 \pm 10.4 \mathrm{~mm}, n=21)$ (Mann-Whitney test, $Z=1.76, P=0.079)$.

Morphological and anatomical traits (SVL, intestine length, stomach and liver mass) were taken from some lizards collected at the same localities and dates. Furthermore, the number of teeth and the cusp number per tooth in the jaws and maxillary bones were counted.

Data Analysis. Data analyses included ANOVA to study differences in lizard body size between the two different islands (and among populations), and ANCOVA (using diameter of fecal pellets as covariates) to compare amount of plant matter in the diet. This approximation was used to control lizard-size effects on diet type and to avoid bias in the diet comparisons among Tenerife lizard localities. The relationship between the proportion of plant in the diet and body size of Canarian lizards is well documented (Mateo and López-Jurado, 1992; Valido, 1999). Also, there is a significant relationship between diameter of fecal pellets and lizard size (Pearson correlation, $r_{p}=0.79, P=0.036$ on log-transformed data; $n=24$ mean diameter of droppings obtained from 24 individuals of G. galloti kept in captivity and with an omnivorous diet). We therefore used droppings diameter as a covariate to control the effects of lizard's size. Analysis of simple regression with the pooled data (with SVL as an independent variable) was used to control for allometric effects in the comparisons of anatomical and physiological characters (Packard and Boardman, 1988). The use of pooled data in the regression analysis is justified because the interaction term (locality $\times$ SVL) in the ANCOVA (using SVL as a covariate and locality as the main effect) is not significant $(P>0.11$ in all the traits), indicating similar regression slopes in the studied populations. Residuals (deviations) of observations for the allometric regressions were retained for ANOVA and multivariate analysis of variance (MANOVA) using a GLM procedure and Type III sums of squares. Throughout the paper, means are accompanied by standard deviations unless otherwise indicated.

\section{Results}

Variation in Diet Composition. Table 1 shows the composition of plant matter and animal prey items in the diet of both species of lizards from the four studied localities. The percentage of total plant matter showed significant differences among the four studied localities (ANOVA, $F=243.45$, df $=3,596, P<0.001$ on arc-sin transformed data), 
with significantly more plant material in the lizard's diet in Teno Bajo $(79 \pm 19 \%, n=150)$ and Bajamar $(81 \pm 18 \%, n=150)$ than Izaña $(21 \pm 25 \%, n=150)$ and Tetir $(28 \pm 30 \%$, $n=150$ ) (Scheffé test, $P<0.001$ ). The frequency distributions of plant matter show similar trends in Teno Bajo and Bajamar (Tenerife), while the opposite tendency was observed in both Izaña (Tenerife) and Tetir (Fuerteventura) populations (fig. 1). All the droppings analyzed in Teno Bajo and Bajamar had some remains of plant matter, while in the other two localities plant material was present in $61 \%$ (Izaña) and 69\% (Tetir) of the droppings analyzed (table 1).

One of the clearest differences is the high values of fleshy fruit remains in the droppings collected from Teno Bajo and Bajamar (66\% and 59\%, respectively), and their near absence in the other two zones: Izaña and Tetir (3\% and 8\%), where other plant parts (basically flowers but leaves too) were more important than fleshy fruits. Therefore, lizards from the high shrub mountain of Izaña (Tenerife) and from the xeric habitats of Fuerteventura (Tetir) were more omnivorous, practically insectivorous, than those from the xerophytic shrub of Teno Bajo and Bajamar (Tenerife).

In the case of the three localities of Tenerife, the difference that appeared in the diet could be related to bias toward collecting droppings from lizards of different body size (e.g. a more representative sample of droppings belonging to small lizards in Izaña, characterized by an insectivorous diet). However, the pattern of intra-insular differences is consistent when controlling the diameter $(\mathrm{mm})$ of droppings analyzed $(6.0 \pm 1.4 \mathrm{~mm}, n=142$ in Teno Bajo, $6.37 \pm 1.4 \mathrm{~mm}, n=149$ in Bajamar and $4.5 \pm 1.4 \mathrm{~mm}, n=147$ for Izaña) (arc-sin transformation; $F=241.15, \mathrm{df}=2,435, P<0.001$ for the ANCOVA of percentage of plant matter as the main effect and diameter of droppings as the covariate), and no significant differences were observed when comparing the percentage of vegetable matter in the droppings of Bajamar and Teno Bajo when controlling the dropping diameter (ANCOVA, $F=0.016$, df $=2,290, P=0.89$ ).

The frequency of small stones (grid) contained in the droppings was remarkely different in the each populations. Teno Bajo $(n=23)$ and Bajamar $(n=20)$ presented the higher numbers to compare with Izaña $(n=5)$ and Tetir $(n=2)$, for the entire sample of droppings analyzed at each locality.

Morphological and Anatomical Traits. Adult lizards from Tetir (G. atlantica) (SVL: $57.0 \pm 3.6 \mathrm{~mm}, n=19$ ) were smaller in size than G. galloti from the localities of Tenerife (Teno Bajo: $105.9 \pm 13.7 \mathrm{~mm}, n=36$; Bajamar: $95.7 \pm 7.1 \mathrm{~mm}, n=15$; Izaña: $105.1 \pm 14.2, N=15$ ) (ANOVA, $F=132.9$, df $=3,81, P<0.001$ on logtransformed data) (table 2). Additionally, no statistical differences were evident among the three G. galloti populations from Tenerife (Scheffé test, $P>0.05$ ).

Despite this clear difference in size between species, no significant differences in anatomical measures were obtained among the lizards of these four localities if variation in SVL is taken into account (MANOVA, Wilks' $\lambda ; F=0.62, P=0.85, N=60$; with residuals from the significant models obtained in the regression analysis of each trait; 

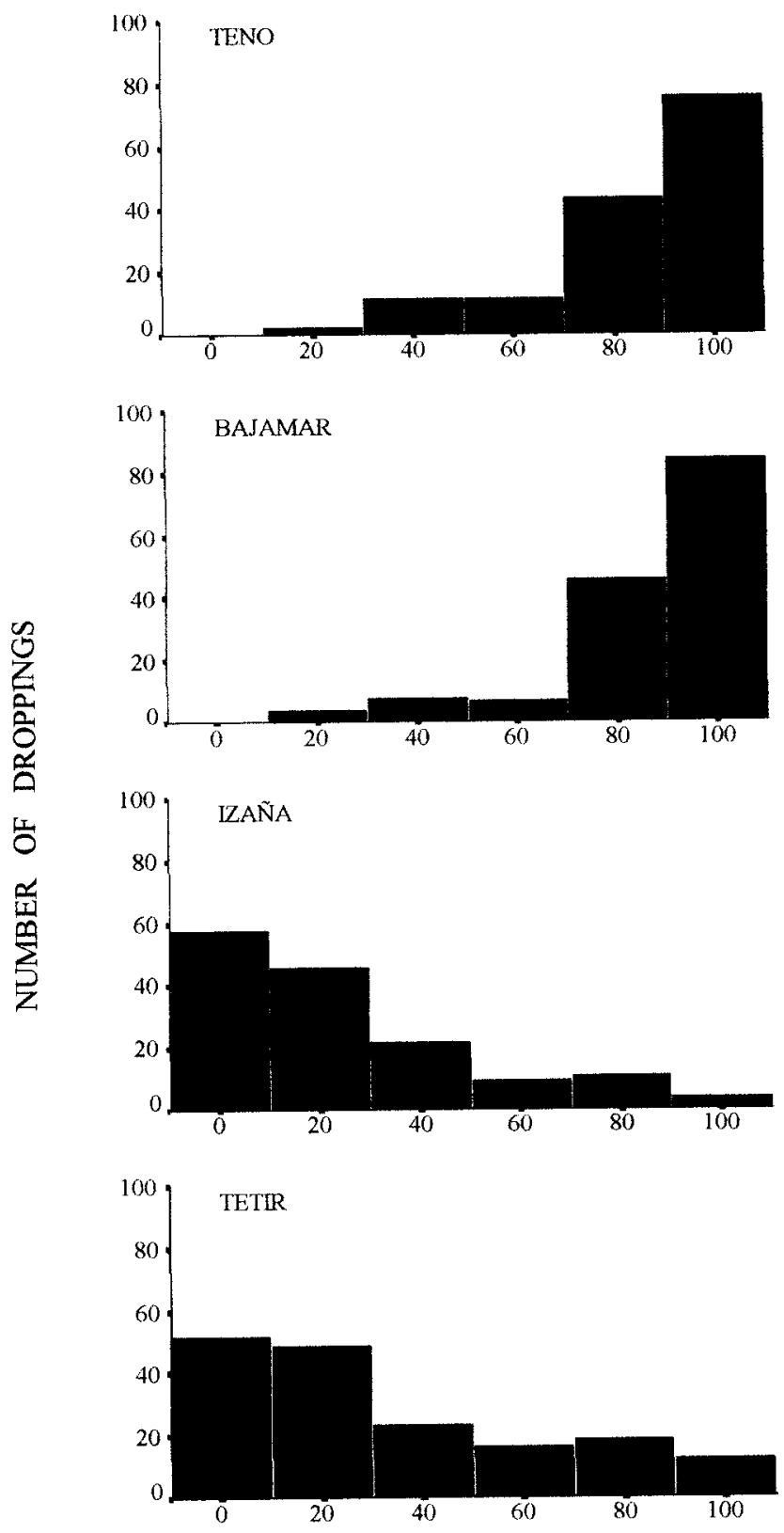

\section{PERCENTAGE OF VEGETABLE MATTER}

Figure 1. Number of droppings and percentage of plant matter (pooled fruits, flowers and leaves) in G. galloti from Teno Bajo, Bajamar and Izaña (Tenerife); and G. atlantica from Tetir (Fuerteventura) $(n=150$ droppings, respectively). 
Table 1. Diet composition in the droppings of Gallotia galloti in Teno Bajo, Bajamar and Izaña (Tenerife) and G. atlantica in Tetir (Fuerteventura) $(n=150$, respectively). \% FO: Frequency of occurrence (percentage of droppings with the taxon present). \% F: percentage of the total seeds and invertebrates found in the droppings.

\begin{tabular}{|c|c|c|c|c|c|c|c|c|}
\hline & \multicolumn{4}{|c|}{ Gallotia galloti } & & & \multirow{2}{*}{\multicolumn{2}{|c|}{$\begin{array}{c}\text { Gallotia atlantica } \\
\text { Tetir }\end{array}$}} \\
\hline & \multicolumn{2}{|c|}{ Teno Bajo } & \multicolumn{2}{|c|}{ Bajamar } & \multicolumn{2}{|c|}{ Izaña } & & \\
\hline & $\% \mathrm{FO}$ & $\% \mathrm{~F}$ & $\% \mathrm{FO}$ & $\% \mathrm{~F}$ & $\% \mathrm{FO}$ & $\% \mathrm{~F}$ & $\% \mathrm{FO}$ & $\% \mathrm{~F}$ \\
\hline \multicolumn{9}{|l|}{ Fruit remains } \\
\hline Rubia fruticosa & 11.3 & 3.9 & 2.7 & 2.7 & - & - & - & - \\
\hline Withania aristata & 5.3 & 0.8 & 2.7 & 3.8 & - & - & - & - \\
\hline Neochamaelea pulverulenta & 2 & 0.2 & - & - & - & - & - & - \\
\hline Lycium intricatum & 1.3 & 0.3 & - & - & - & - & - & - \\
\hline Plocama pendula & 46 & 86.1 & - & - & - & - & - & - \\
\hline Opuntia dillenii & 26.7 & 6.0 & - & - & - & - & - & - \\
\hline Opuntia maxima & - & - & 3.3 & 2.2 & - & - & - & - \\
\hline Atriplex semibaccata & 0.7 & 0.1 & 6.7 & 6.3 & - & - & 2 & 17.2 \\
\hline Spartocytisus supranubius & - & - & - & - & 9.3 & 88.9 & - & - \\
\hline Ficus carica & - & - & 19.3 & 66.3 & - & - & 9.3 & 81 \\
\hline Asparagus pastorianus & - & - & 20 & 9.3 & - & - & - & - \\
\hline Asparagus umbellatus & - & - & 1.3 & 0.4 & - & - & - & - \\
\hline Bosea yervamora & - & - & 26 & 9.1 & - & - & - & - \\
\hline Undetermined & 2 & 2.6 & 2 & 1 & 1.3 & 11.1 & 0.7 & 1.7 \\
\hline \multicolumn{9}{|l|}{ Invertebrates } \\
\hline Coleoptera & 6.7 & 18.2 & 2 & 8.8 & 40 & 29.5 & 21.3 & 12.9 \\
\hline Hemiptera & 2.7 & 7.3 & 1.3 & 5.9 & 22 & 18.4 & 3.3 & 1.9 \\
\hline Diptera & 6 & 16.4 & 12 & 58.8 & 12.7 & 12.3 & 2.7 & 2.7 \\
\hline Formicidae & 10.7 & 50.9 & 6 & 26.5 & 19.3 & 25.4 & 34.7 & 72.6 \\
\hline Other Hymenoptera & 2 & 5.5 & - & - & 15.3 & 13.1 & 4 & 3 \\
\hline Orthoptera & 0.7 & 1.8 & - & - & 2 & 1.2 & 2.7 & 1.5 \\
\hline \multirow[t]{2}{*}{ Gasteropoda } & - & - & - & - & - & - & 9.3 & 5.3 \\
\hline & $n$ & $\%$ & $n$ & $\%$ & $n$ & $\%$ & $n$ & $\%$ \\
\hline Droppings with plant matter & 150 & 100 & 150 & 100 & 92 & 61.3 & 104 & 69.3 \\
\hline Droppings with only plant matter & 23 & 15.3 & 22 & 14.7 & 0 & 0 & 1 & 0.7 \\
\hline Droppings with invertebrates & 127 & 84.7 & 128 & 85.3 & 150 & 100 & 149 & 99.3 \\
\hline Droppings with only invertebrates & 0 & 0 & 0 & 0 & 58 & 38.7 & 46 & 30.7 \\
\hline$\%$ volume of fruit remains & \multicolumn{2}{|c|}{66.3} & \multicolumn{2}{|c|}{59.3} & \multicolumn{2}{|c|}{3.3} & \multicolumn{2}{|c|}{8.4} \\
\hline$\%$ volume of other plant parts & \multicolumn{2}{|c|}{12.5} & \multicolumn{2}{|c|}{21.6} & \multicolumn{2}{|c|}{17.3} & \multicolumn{2}{|c|}{19.9} \\
\hline
\end{tabular}

see table 2). These results confirm that apparent differences between species, or among populations, are clearly associated with differences in lizard size. An example of this pattern is the positive relationship observed between intestine length and SVL in each population (Teno Bajo: $r_{s}=0.42, P=0.015$, Bajamar: $r_{s}=0.32, P=0.24$, Izaña: $r_{s}=0.79, P<0.001$, and Tetir: $r_{s}=0.41, P=0.078$ ).

Both species have heterodont dentition and cylindrical teeth attached to the jaw in the pleurodont fashion. Gallotia atlantica shows two cusps per tooth (back cusp bigger in size) occupying practically all the dentary except 4-6 unicusp teeth located in the anterior part. 
Table 2. Descriptive statistics of morphological and anatomical traits of G. galloti in Teno Bajo, Bajamar and Izaña (Tenerife), and G. atlantica in Tetir (Fuerteventura). Number of teeth and cusps have been counted in one jaw per individual. Data are mean $\pm 1 s$ (sample size in brackets).

\begin{tabular}{lcccr}
\hline & \multicolumn{3}{c}{ Gallotia galloti } & Gallotia atlantica \\
\cline { 2 - 4 } & \multicolumn{1}{c}{ Teno Bajo } & Bajamar & Izaña & Tetir \\
\hline SVL (mm) & $119.0 \pm 13.4(119)$ & $95.7 \pm 7.1(15)$ & $103.0 \pm 13.1(33)$ & $60.8 \pm 9.9(65)$ \\
Intestine length (mm) & $190.6 \pm 39.2(32)$ & $130.9 \pm 24.4(16)$ & $164.1 \pm 34.2(15)$ & $85.3 \pm 14.7(19)$ \\
Stomach mass (g) & $0.3 \pm 0.2(33)$ & $0.3 \pm 0.1(16)$ & $0.3 \pm 0.1(15)$ & $0.1 \pm 0.1(19)$ \\
Liver mass (g) & $0.9 \pm 0.3(33)$ & $0.6 \pm 0.2(16)$ & $1.2 \pm 0.5(15)$ & $0.2 \pm 0.2(19)$ \\
Number of teeth & $18.4 \pm 2.3(18)$ & $18.2 \pm 1.7(16)$ & $18.8 \pm 0.9(13)$ & $17.4 \pm 0.9(18)$ \\
Number of cusps & $44.3 \pm 3.7(18)$ & $44.1 \pm 2.1(16)$ & $44.5 \pm 1.8(13)$ & $29.8 \pm 1.8(18)$ \\
\hline
\end{tabular}

Gallotia galloti also presents three cusps per tooth distributed in nearly all the dentary except 4-5 unicusp teeth in the anterior part. The central cusp of each tooth is clearly more developed than the lateral cusps, and this pattern is very similar among the three studied lizard populations from Tenerife.

Physiological Traits. GPT was shorter in the Tetir individuals ( $2.4 \pm 1.5$ days; Range $=0.6-5.9$ days) than both those from Izaña $(6.1 \pm 5.3$ days; Range $=0.7-25.7$ days $)$ and Teno Bajo (6.9 \pm 3.8 days; Range $=2.3-19.0$ days) under a similar diet in captivity. This is an expected result because $G$. atlantica has a much shorter digestive tract or SVL than G. galloti (see table 2). However, this apparent difference between species is not confirmed when the difference in size of the lizards is controlled by residual analysis (ANOVA, $F=0.124$, df $=2,59, P=0.88$ ); in this sense, obviously larger sizes generate higher GPT values. Furthermore, no significant differences between the two populations studied in Tenerife (Teno Bajo and Izaña) were observed (Scheffé test, $P>0.05$ ), although a significant difference in the diet was detected in the wild.

We calculated the food passage rate (hereafter FPR) by the ratio: SVL/GPT. Differences in FPR were only marginally significant, being slower in the lizards from Teno Bajo $(20.93 \pm 10.33 \mathrm{~mm} \mathrm{SVL/day)}$ relative to Tetir $(36.7 \pm 25.9 \mathrm{~mm} \mathrm{SVL} /$ day) (ANOVA, $F=3.24$, df $=2,58, P=0.046$ ) (fig. 2). Lizards from Izaña showed intermediate values $(23.4 \pm 13.3 \mathrm{~mm} /$ day) and did not differ from the other two localities (Scheffé test, $P>0.05)$. Furthermore, a high individual variation was observed in the three populations ranges: 5.2-44.3 mm/day (Teno Bajo); 3.8-56.1 mm/day (Izaña); 10.1-87.3 mm/day (Tetir).

In the case of Teno Bajo lizards, GPT obtained under laboratory conditions $(6.9 \pm$ 3.8 days, $n=21)$ was similar to field trials (7.2 \pm 2.6 days, $n=13)$ (Mann-Whitney test, $Z=0.87, P=0.38$ ); this pattern is also observed in the case of the FPR ( $Z=1.33$, $P=0.18$ ). Therefore, these results confirm that data from the laboratory experiments agree with those obtained under natural conditions. 


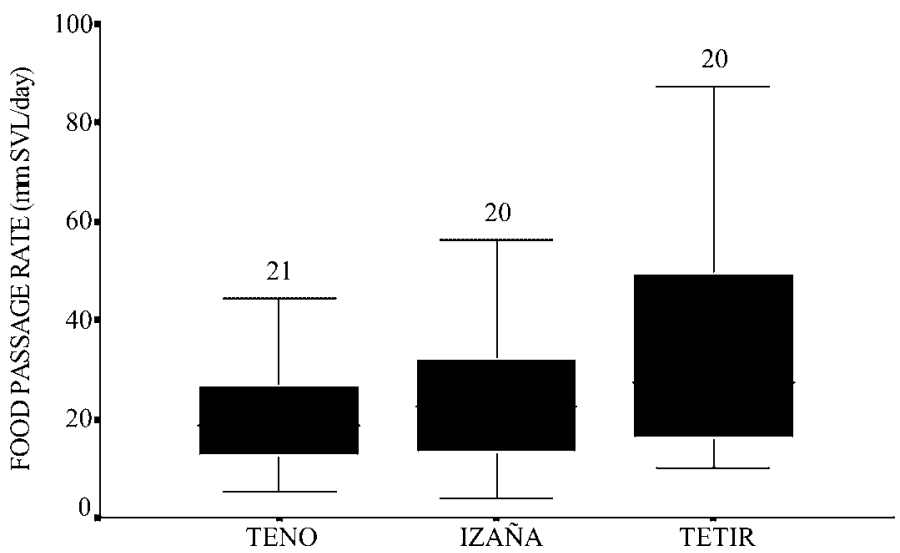

Figure 2. Food passage rate (FPR) (mm SVL/day) found in the lizards from the three localities studied: Teno Bajo and Izaña (Tenerife) and Tetir (Fuerteventura). The box indicates the mean ( $\pm 1 \mathrm{SE})$. The bars extending above and below each box show the maximum and minimum values. Sample sizes are also indicated.

\section{Discussion}

Diet Composition and Variation. Analyses of faecal pellets from the four populations studied indicate that these lizards showed a remarkable omnivorous diet. However, an important variation in diet composition at both intra and inter-specific levels was observed. Lizards from Teno Bajo and Bajamar (Tenerife) are omnivorous, basically frugivorous, while individuals from Izaña (Tenerife) and Tetir (Fuerteventura) are omnivorous, basically insectivorous. These results are also in agreement with previous studies, which show an omnivorous diet in these species (Lönnberg, 1902; Klemmer, 1976; Díaz, 1980; Valido and Nogales, 1994; López-Jurado and Mateo, 1995; Nogales et al., 1998).

Although we lack estimates of resource abundance in these localities, the observed differences in the diet could be attributable to abundance variations in food item, both between islands and among habitats. In this respect, some authors such as Pérez-Mellado and Corti (1993), Van Damme (1999), and Cooper and Vitt (2002) have mentioned that the limitation of animal prey availability in insular environments, which together with the density compensation suffered by the island lizards (Olesen and Valido, 2003), has been one of the main factors that might explain the higher occurrence of plant matter in the diet of insular lizards with respect to their mainland relatives.

Although this pattern has been used to compare mainland and island habitats, this tendency could also explain differences among islands within an archipelago (Schluter, 1984), and also between habitats within islands, but this aspect is still rather unknown. Additionally, lizard size (lesser in G. atlantica from Fuerteventura) can also contribute to increased differences in the degree of herbivory between the two species.

Morphological and Anatomical Traits. The digestive system in these lizards shows differences that are correlated with the amount of the energetically diluted food components in 
the diet (Lönnberg, 1902; Skoczylas, 1978; King, 1996). This fact confirms the predictions raised in this study based on optimal digestion theory of energetically poor diets (Sibly, 1981). The lizard species with a more energy-poor diet (G. galloti) is larger in size and this permits them to have (secondarily) more effective anatomical and physiological traits to maintain a higher digestive efficiency when feeding on vegetable matter. Extensive use of plant matter, as a main food resource, is constrained by body size (allometric constraint hypothesis). Smaller lizards have higher energy requirements relative to body size (Pough, 1973; Troyer, 1984; Mautz and Nagy, 1987;Zimmerman and Tracy, 1989;Zari, 1991) and for this reason, the majority of 'small' species show a marked preference for a diet based on invertebrates (Ostrom, 1963; Sokol, 1967; Pough, 1973; Greene, 1982; Demment and Van Soest, 1985; Bozinovic, 1993; King, 1996; Van Damme, 1999). Furthermore, Ostrom (1963) and Sokol (1967) indicated that smaller lizards do not have sufficient jaw power to crush plant matter efficiently; therefore, only large lizards can successfully exploit it. However, some authors such as Johnson and Lillywhite (1979) and King (1996) have criticized this interpretation.

According to Pough's model on the relationship between lizard size and diet, it is interesting to note that G. galloti from Teno Bajo and Bajamar (the species does not normally exceed $55 \mathrm{~g}$ ) shows a marked tendency forward herbivory even with a smaller size than other lizards belonging to the families Agamidae, Iguanidae, Scincidae, Gerrhosauridae and Cordylidae (Pough, 1973). However more extreme deviations from this model are known, and expected, under particular ecological situations, such as low predation risk, behavioral and/or physiological mechanisms, resource availability and thermoregulatory behavior (Pough, 1973; Throckmorton, 1973; Johnson and Lillywhite, 1979; Greene, 1982; Van Devender, 1982; Schluter, 1984; Waldschmidt et al., 1986; Mautz and Nagy, 1987; Zimmerman and Tracy, 1989; Van Marken Lichtenbelt, 1992; Bozinovic, 1993; Dearing, 1993; Van Damme, 1999). Furthermore, it is interesting to note that those lizard species in which poor-fiber plant parts (fruits and flowers) constitute the main part of the plant component do not show specific anatomical traits to digest cellulose as occurs in folivorous lizard species (Iverson, 1982; Cooper and Vitt, 2002). This could explain why herbivory is relatively more common among small lizards (see reviews in Greene, 1982; Van Damme, 1999 and Cooper and Vitt, 2002) than expected under Pough's model. In this respect, the size of organs will be larger according to a general increase in body size (allometric related; see e.g. Carretero 1993 for some lacertid species). For example, with respect to the intestine length, an increase of the absorption surface would be important for lizards with qualitatively poor diets due to the increase in digestion rate and nutrient absorption efficiency.

The number of cusps per tooth has been suggested to be adaptively variable among lizards in relation to herbivory (Hotton, 1955; Montanucci, 1968; Johnson and Lillywhite, 1979; Zimmerman and Tracy, 1989; Mateo and López-Jurado, 1992) because the cusps have potentially a shearing function and could be used for reducing plant materials (Sokol, 1967). Nevertheless, the presence of teeth without cusps and the absence of a clear 
mastication have been pointed out as central traits of typically herbivorous species (Ostrom, 1963; Throckmorton, 1973 and 1976).

Besides, this degree of shearing of plant matter would also be favored by the ingestion of small stones (lithophagy) (Sokol, 1971; Skoczylas, 1978). This tendency has also been observed in our studied organisms where a higher number of stones (grit) was found in Teno Bajo and Bajamar than Izaña and Tetir. This comparative feeding behavior would be a good solution that does not require any remarkable change in digestive anatomy, and suitable for all in habitats where the resource availability and abundance is unpredictable.

PhysiologicalTraits. Physiologicalvariables measured in the Canarian lizard populations follow the general patterns previously reported by several authors for different lizard species along an insectivory-herbivory gradient. Long transit times (about three to seven days) have been mentioned for different herbivorous lizard species (Throckmorton, 1973; Johnson and Lillywhite, 1979; Christian et al., 1984; Waldschmidt et al., 1986; Mautz and Nagy, 1987; Zimmerman and Tracy, 1989), while values shorter values than two days have been observed among insectivorous ones (Taddei, 1951; Avery, 1973; Windel and Sarokon, 1976; Zimmerman and Tracy, 1989).

These long retention times of the plant food in the gut are necessary to increase digestive efficiency (Throckmorton, 1973; Johnson and Lillywhite, 1979; Iverson, 1982; Christian et al., 1984; Troyer, 1984; Zimmerman and Tracy, 1989). The absence of differences between the lizards from Teno Bajo and Izaña, during the GPT experiments, could be a consequence of their maintenance under a similar diet. Therefore, it might be possible that under natural conditions the Izaña lizards (with a basically insectivorous diet) will present a shorter GPT, in accordance with the predictions of Sibly (1981). In this respect, a different thermoregulatory behavior can produce a shorter GPT (Throckmorton, 1973; Waldschmidt et al., 1986; Mautz and Nagy, 1987; Zimmerman and Tracy, 1989; Van Marken Lichtenbelt, 1992), and this functional change could be more advantageous ecologically and evolutionarily, than anatomical modifications.

Conclusions. No special anatomical or physiological adaptations were observed in the omnivorous Canarian lizards studied. Body size was the major determinant explaining the level of herbivory (or frugivory) in these omnivorous lizards; in the latter case, large body size facilitates the exploitation of fruits and the lizards function importantly as mutualistic agents in the seed-dispersal of plants (Valido, 1999).

On the other hand, herbivory in island lizards could be related to a lower density of arthropods in oceanic islands (Janzen, 1973; Van Damme, 1999; Cooper and Vitt, 2002). This could explain the tendency of Izaña lizards to show an more insectivorous diet with respect to the Bajamar and Teno populations, probably due to a higher arthropod abundance in this locality when this study was performed (Valido, 1999). Besides, differences in the amount of arthropods in the lizard diet, and their relationship with the abundance of insects, has been observed in some localities in the high mountain shrub of Tenerife where a systematic sampling of arthropods was realized (Oromí et al., 1996; Valido, 1999). 
In adition, the Canarian lizards show preferences for arthropods when both food items (insects and plants) are available (A. Valido, personal observation with captive lizads; see also Schuter, 1984 in the case of the Galápagos lava lizard).

Another argument that could explain the absence of anatomical or physiological adaptations to the herbivorous diet is that these lizards show an important temporal and spatial variation of plant material in the diet during the year. In this respect, it was observed that the vegetal component ranged between $23.1 \%$ (January) - 79.3\% (April) in the case of G. galloti in Teno Bajo and it is a normal response in different Canarian lizards inhabiting several habitats through the year (Valido, 1999). This seasonal diet change could be limiting the evolution of permanent anatomical adaptations in these lizards (as has been observed in frugivorous birds; Herrera, 1984; Jordano, 1987), and other behavioral changes like thermoregulatory behavior, ingesting small stones which are less costly and more ecological and evolutionarily advantageous for generalist lizards.

Acknowledgements. We thank Luisa Hernández and Manuel Valido 'Pololo' for assisting us during the follow up of the GPT experiments. Félix Medina 'Feluco' and Juan Carlos Sánchez captured some lizards and provided us with preserved specimens, respectively. Jaime Urioste gave us insects during the GPT experimental period, and the Servicio Electrónico de la Universidad de La Laguna assembled the control system of the climatic chamber. Pedro Jordano helped us to plan the experiments and encouraged in several ways at all stages of development of this study. Mario Díaz and specially Pedro Jordano, Francisco Bozinovic, Donald B. Miles, Raoul Van Damme and two anonymous referees improved an initial manuscript with useful comments. The control system used in the GPT experiments was supported by Dirección General de Universidades e Investigación del Gobierno de Canarias (grant 93/150).

\section{References}

Avery, R.A. (1973): Morphometric and functional studies on the stomach of the lizard Lacerta vivipara. J. Zool. 169: $157-167$.

Bozinovic, F. (1993): Fisiología ecológica de la alimentación y digestión en vertebrados: modelos y teorías. Rev. Chil. Hist. Nat. 66: 375-382.

Carretero, M.A. (1997): Digestive size and diet in Lacertidae: a preliminary analysis. In: Herpetologia Bonnensis, p. 43-49. Böhme, W., Bischoff, W., Ziegler, T., Eds, Bonn, S.E.H.

Chivers, D.J., Hladik, C.M. (1980): Morphology of the gastrointestinal tract in primates: comparisons with other mammals in relation to diet. J. Morphol. 166: 337-386.

Christian, K.A., Tracy, A.C., Porter, W.P. (1984): Diet, digestion, and food preferences of Galápagos land iguanas. Herpetologica 40: 205-212.

Cooper, W.E., Vitt, L.V. (2002): Distribution, extent, and evolution of plant consumption by lizards. J. Zool., Lond. 257: 487-517.

Dearing, M.D. (1993): An alimentary specialization for herbivory in the Tropical Whiptail lizard Cnemidophorus murinus. J. Herpetol. 27: 111-114.

Demment, M.W., Van Soest, P.J. (1985): A nutritional explanation for body-size patterns of ruminant and nonruminant herbivores. Am. Nat. 125: 641-672.

Díaz, E. (1980): Notas sobre el lagarto tizón (Lacerta galloti). Doñana, Acta Vert. 7: 95-96.

Díaz, J.A. (1994): Field thermoregulatory behavior in the western Canarian lizard Gallotia galloti. J. Herpetol. 28: 325-333.

Fu, J. (1998): Toward the phylogeny of the family Lacertidae: implications from mitochondrial DNA 12s and 16s gene sequences (Reptilia: Squamata). Mol. Phyl. Evol. 9: 118-130. 
González, P., Pinto, F., Nogales, M., Jiménez-Asensio, J., Hernández, M., Cabrera, V. (1996): Phylogenetic relationships of the Canary Islands endemic lizard genus Gallotia (Sauria: Lacertidae), inferred from mitochondrial DNA sequences. Mol. Phyl. Evol. 5: 63-71.

Greene, H.W. (1982): Dietary and phenotypic diversity in lizards: why are some organisms specialized? In: Environmental adaptation and evolution, p. 107-128. Mossakowski, D., Roth, G., Eds, Stuttgart, Gustav Fischer.

Greer, A.E. (1976): On the evolution of the giant Cape Verde scincid lizard Macroscincus coctei. J. Nat. Hist. 10: 691-712.

Guard, C.L. (1980): The reptilian digestive system: general characteristics. In: Comparative Physiology:Primitive Mammals, p. 43-51. Schmidt-Nielsen, K., Bolis, L., Taylor, C.R., Eds, Cambridge, Cambridge University Press.

Herrera, C.M. (1984): Adaptation to frugivory of Mediterranean avian seed dispersers. Ecology 65: 609-617.

Hotton, N. (1955): A survey of adaptive relationships of dentition to diet in North America Iguanidae. Am. Midl. Nat. 55: 88-114.

Iverson, J.B. (1982): Adaptations to herbivory in iguanine lizards. In: Iguanas of the World: their Behavior, Ecology and Conservation, p. 60-76. Burghardt, G.M., Rand, A.S., Eds, New Jersey, Noyes, Park Ridge.

Janzen, D.H. (1973): Sweep samples of tropical foliage insects: effects of seasons, vegetation types, elevation, time of day, and insularity. Ecology 54: 687-701.

Johnson, R.N., Lillywhite, H.B. (1979): Digestive efficiency of the omnivorous lizard Klauberina reversiana. Copeia 1979: 431-437.

Jordano, P. (1987): Frugivory, external morphology and digestive system in mediterranean sylviid warblers Sylvia spp. Ibis 129: 175-189.

Jordano, P. (2000): Fruits and frugivory. In: Seeds, the Ecology of Regeneration in Plant Communities, p. $125-$ 165. Fenner, M., Ed., Wallingford, Commonwealth Agricultural Bureau International.

Karasov, W.H. (1986): Energetics, physiology and vertebrate ecology. Trends Ecol. Evol. 1: 101-104.

King, G. (1996): Reptiles and Herbivory. London, Chapman and Hall.

Klemmer, K. (1976): The amphibia and reptilia of the Canary Islands. In: Biogeography and Ecology in the Canary Islands. Monographia Biologica 30, p. 433-456. Kunkel, G., Ed., The Netherlands, The Hague, W. Junk Publishers.

Lönnberg, E. (1902): On some points of relation between the morphological structure of the intestine and the diet of reptiles. Bihang Till K. Svenska Vet.-Akad. Handlingar 28: 1-51.

López-Jurado, L.F., Mateo, J.A. (1995): Origin, colonization, adaptive radiation, intrainsular evolution and species substitution processes in the fossil and living lizards of the Canary Islands. In: Scienta Herpetologica, p. 81-91. Llorente, G.A., Montori, A., Santos, X., Carretero, M.A., Eds, Barcelona, S.E.H.

Márquez, R., Cejudo, D., Pérez-Mellado, V. (1997): Selected body temperatures of four lacertid lizards from the Canary Islands. Herpetol. J. 7: 122-124.

Mateo, J.A., López-Jurado, L.F. (1992): Study of dentition in lizards from Gran Canaria Island (Canary Islands) and its ecological and evolutionary significance. Biol. J. Linn. Soc. 46: 39-48.

Mautz, W.J., Nagy, K.G. (1987): Ontogenetic change in diet, field metabolic rate, and water flux in the herbivorous lizard Dipsosaurus dorsalis. Physiol. Zool. 60: 640-658.

Montanucci, R.R. (1968): Comparative dentition in four iguanid lizards. Herpetologica 24: 305-315.

Nogales, M., Delgado, J.D., Medina, F.M. (1998): Shrikes, lizards and Lycium intricatum (Solanaceae) fruits: a case of indirect seed dispersal on an oceanic island (Alegranza, Canary Islands). J. Ecol. 86: 866-871.

Olesen, J.M., Valido, A. (2003): Lizards as pollinators and seed dispersers: A island phenomenon. Trends Ecol. Evol. 18 (4): 177-181.

Oromí, P., Zurita, N., Arechavaleta, M., Camacho, A. (1996): Inventario de la fauna de invertebrados del Parque Nacional del Teide. II Estudio de las comunidades de invertebrados. Depto. de Biología Animal. Universidad de La Laguna (unpublished report), pp. 370.

Ostrom, J.H. (1963): Further comments on herbivorous lizards. Evolution 17: 368-369.

Packard, G.C., Boardman, T.J. (1988): The misuse of ratios, indices, and percentages in ecophysiological research. Physiol. Zool. 61: 1-9.

Pérez-Mellado, V., Corti, C. (1993): Dietary adaptations and herbivory in lacertid lizards of the genus Podarcis from western Mediterranean islands (Reptilia: Sauria). Bonn. zool. Beitr. 44: 193-220. 
Pérez-Mellado, V., Romero-Beviá, M., Ortega, F., Martín-García, S., Perera, A., López-Vicente, M., Galache, C. (1999): El uso de los recursos tróficos en Gallotia simonyi (Sauria Lacertidae) de la isla de El Hierro (Islas Canarias). In: El Lagarto Gigante de El Hierro. Bases para su Conservación, p. 63-84. López-Jurado, L.F., Mateo, J.A., Eds, Asociación Herpetológica Española.

Pough, H. (1973): Lizard energetic and diet. Ecology 54: 837-844.

Schluter, D. (1984): Body size, prey size and herbivory in the Galápagos lava lizard Tropidurus. Oikos 43: 291300.

Sibly, R.M. (1981): Strategies of digestion and defecation. In: Physiological Ecology, an Evolutionary Approach to Resource Use, p. 109-139. Townsend, C.R., Calow, P., Eds, London, Blackwell Scientific Publications.

Skoczylas, R. (1978): Physiology of the digestive tract. In: Biology of the Reptilia, vol. 8, p. 589-717. Gans, C., Tinkle, D.W., Eds, London, Academic Press.

Sokol, O.M. (1967): Herbivory in lizards. Evolution 21: 192-194.

Sokol, O.M. (1971): Lithophagy and geophagy in reptiles. J. Herpetol. 5: 69-70.

Szarski, H. (1962): Some remarks on herbivorous lizards. Evolution 16: 529.

Taddei, A. (1951): Contibuto allo studio del canale alimentaire in Lacerta. Boll. Zool. 18: 291-294.

Throckmorton, G.S. (1973): Digestive efficiency in the herbivorous lizard Ctenosaura pectinata. Copeia 1973: 431-435.

Throckmorton, G.S. (1976): Oral food processing in two herbivorous lizards, Iguana iguana (Iguanidae) and Uromastix aegyptius (Agamidae). J. Morphol. 148: 363-390.

Troyer, K. (1984): Diet selection and digestion in Iguanaiguana: the importance of age and nutrient requirements. Oecologia 61: 201-207.

Valido, A. (1999): Ecología de la dispersión de semillas por los lagartos endémicos canarios (g. Gallotia, Lacertidae). PhD Thesis, University of La Laguna, Tenerife.

Valido, A., Nogales, M. (1994): Frugivory and seed dispersal by the lizard Gallotia galloti (Lacertidae) in a xeric habitat of the Canary Islands. Oikos 70: 403-411.

Van Damme, R. (1999): Evolution of herbivory in lacertid lizards: effects of insularity and body size. J. Herpetol. 33: 663-674.

Van Devender, R.W. (1982): Growth and Ecology of Spiny-Tailed and Green Iguanas in Costa Rica, with comments on the evolution of herbivory and large body size. In: Iguanas of the World, pp. 162-183. Burgharat, G.M., Rand, A.S., Eds, New Jersey, Noyes publ. Park Ridge.

Van Marken Lichtenbelt, W. (1992): Digestion in an ectothermic herbivore, the green Iguana (Iguana iguana): effect of food composition and body temperature. Physiol. Zool. 65: 649-673.

Waldschmidt, S.R., Jones, S.M., Porter, W.P. (1986): The effect of body temperature and feeding regime on activity, passage time and digestive coefficient in the lizard Uta stansburiana. Physiol. Zool. 59: 376-383.

Windell, J.T., Sarokon, J.A. (1976): Rate of gastric evacuation in the lizard Anolis carolinensis (Sauria: Iguanidae). Herpetologica 32: 18-23.

Zari, T.A. (1991): The influence of body mass and temperature on the standard metabolic rate of the herbivorous desert lizard, Uromastyx microlepis. J. Therm. Biol. 16: 129-133.

Zimmerman, L.C., Tracy, C.R. (1989): Interactions between environments and ectothermic and herbivory in reptiles. Physiol. Zool. 62: 374-409.

Ziswiler, V., Farner, D.S. (1972): Digestion and the digestive system. In: Avian Biology Vol. II., p. 343-430. Farner, D.S., King, J.R., Parkes, K.X., Eds, New York, Academic Press.

Zug, G.R. (1993): Herpetology, an Introductory Biology of Amphibians and Reptiles. Academic Press, San Diego.

Received: August 31, 2002. Accepted: January 20, 2003. 